\title{
Isolation and characterization of Pseudomonas putida mutants affected in arginine, ornithine and citrulline catabolism: function of the arginine oxidase and arginine succinyltransferase pathways
}

\author{
C. Tricot, ${ }^{1}$ V. Stalon ${ }^{1 *}$ and C. Legrain ${ }^{2}$ \\ ${ }^{1}$ Laboratoire de Microbiologie, Faculté des Sciences, Université Libre de Bruxelles and ${ }^{2}$ Institut de Recherches du CERIA, \\ 1 avenue E. Gryson, B-1070 Bruxelles, Belgium
}

(Received 20 May 1991; revised 26 July 1991; accepted 12 September 1991)

\begin{abstract}
Pseudomonas putida mutants impaired in the utilization of arginine are affected in either the arginine succinyltransferase pathway, the arginine oxidase route, or both. However, mutants affected in one of the pathways still grow on arginine as sole carbon source. Analysis of the products excreted by both wild-type and mutant strains suggests that arginine is mainly channelled by the oxidase route. Proline non-utilizing mutants are also affected in ornithine utilization, confirming the role of proline as an intermediate in ornithine catabolism. Mutants affected in ornithine cyclodeaminase activity still grow on proline and become unable to use ornithine. Both proline non-utilizing mutants and ornithine-cyclodeaminase-minus mutants are unable to use citrulline. These results, together with induction of ornithine cyclodeaminase when wild-type $P$. putida is grown on citrulline, indicate that utilization of citrulline as a carbon source proceeds via proline with ornithine as an intermediate. Thus in $P$. putida, the aerobic catabolism of arginine on the one hand and citrulline and ornithine on the other proceed by quite different metabolic segments.
\end{abstract}

\section{Introduction}

Four arginine catabolic pathways are known in Pseudomonas putida (Fig. 1). The arginine deiminase pathway allows the use of arginine as a cellular ATP source under conditions of energy depletion (Stalon et al., 1972; Stalon $\&$ Mercenier, 1984). The arginine decarboxylase pathway serves mainly for the production of polyamines under conditions of arginine abundance (Stalon \& Mercenier, 1984). Two other pathways, the oxidase route (Miller \& Rodwell, 1971) and the arginine succinyltransferase pathway (Stalon et al., 1987) seem to be involved in the aerobic carbon catabolism of arginine. The fractional flow of intermediates along either of these arginine catabolic pathways is unknown. Characterization of structural or regulatory mutations affecting each pathway would provide a better insight into the nature and significance of the multiple routes. With the aim of assessing the physiological role of the arginine oxidase and arginine succinyltransferase routes, we have isolated mutants blocked in both pathways. We have also investigated the metabolism of ornithine in $P$. putida. Ornithine catabolism in $P$. aeruginosa requires as the first step succinylation of the $\alpha$-nitrogen atom of ornithine (Vander Wauven et al., 1988). From succinylornithine, catabolism of ornithine uses, in this strain, metabolic segments common to the arginine succinyltransferase pathway (Jann et al., 1986; Vander Wauven et al., 1988). Succinylation of ornithine is common among Pseudomonas strains as well as in Aeromonas and the enterobacterium Klebsiella aerogenes, all of which are able to use ornithine as sole carbon source (Stalon et al., 1987). P. putida seems to be devoid of ornithine succinyltransferase activity (Stalon et al., 1987). We found, however, that $P$. putida converts ornithine to proline. The participation of an ornithine cyclodeaminase in the catabolism of ornithine has now been ascertained by the isolation of mutants affected in this activity and in proline utilization.

\section{Methods}

Bacterial strains and growth media. All mutants are derived from $P$. putida IRC204 (Stalon et al., 1967). Strains were grown routinely at $30^{\circ} \mathrm{C}$ in nitrogen-free minimal medium 154 (Stalon et al., 1967). Substrates used as a carbon source or nitrogen source were added after separate sterilization. When used as a carbon source the final concentration of substrates was $20 \mathrm{mM}$. When used as a nitrogen source, substrates were usually included at a final concentration of $10 \mathrm{~mm}$. 


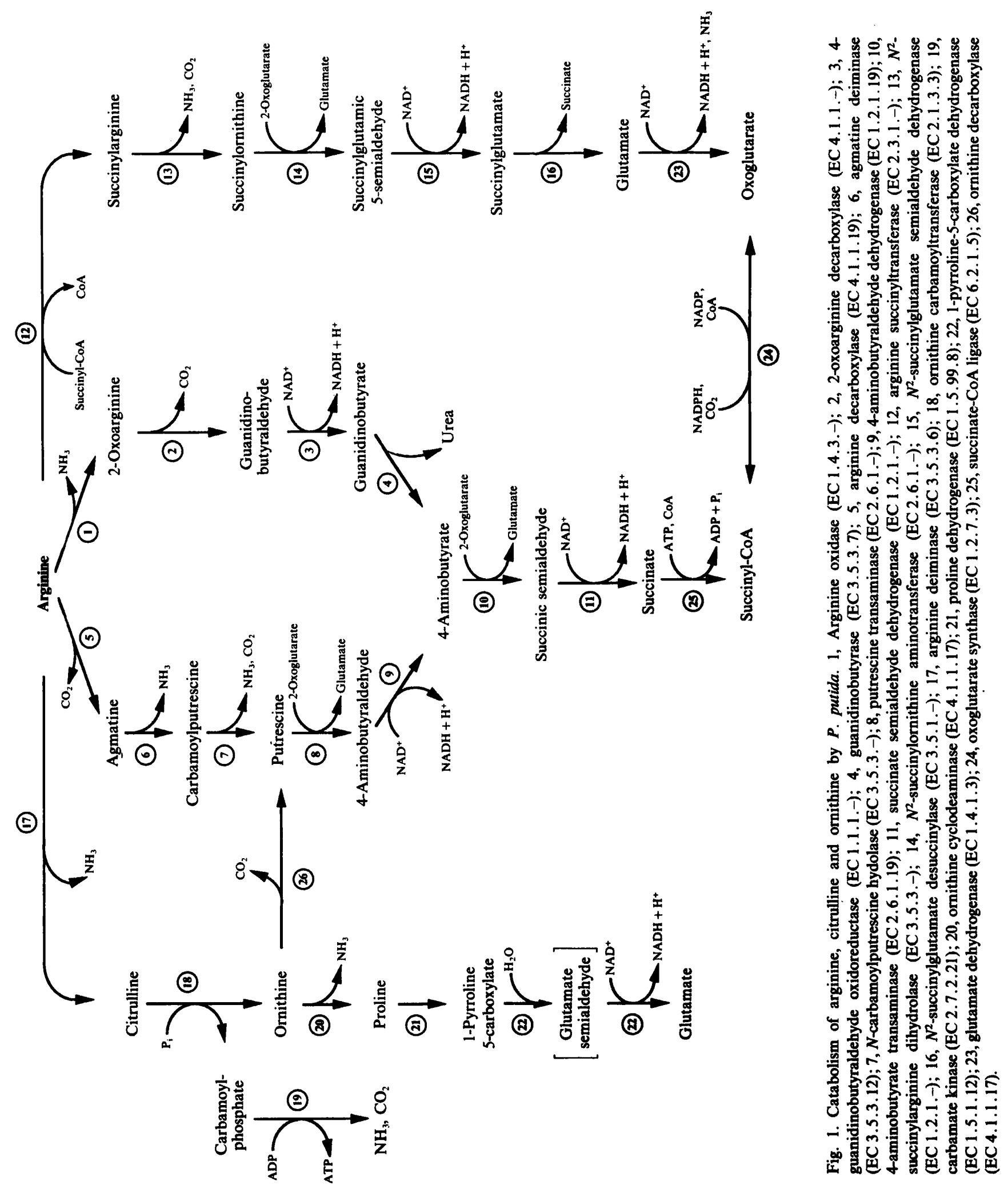


Strains were tested for their ability to grow at the expense of arginine, citrulline, ornithine and potential intermediates in their catabolism. The tests were done in liquid media where substrate consumption and product excretion could be measured. To prepare inocula for substrate utilization studies, $3 \mathrm{ml}$ of rich medium was inoculated from a slant and incubated overnight. Cells were washed twice with $\mathrm{NaCl}(0.9 \%$,w/v) and then used to inoculate $3 \mathrm{ml}$ of standard salt medium 154 at $10^{7}$ cells $\mathrm{ml}^{-1}$. Test-tubes were shaken and bacterial growth was followed by eye. For enzyme activity determination, cultures were grown in $100 \mathrm{ml}$ batches in 1 litre flasks on a rotary shaker. Cells were harvested in the mid-exponential phase of growth, washed twice with $\mathrm{NaCl}(0.9 \%)$ and stored at $-20{ }^{\circ} \mathrm{C}$. Bacterial growth was followed by measuring the optical density at $660 \mathrm{~nm}$ with a Beckman photometer.

Isolation of mutants. $N$-methyl- $N^{\prime}$-nitro- $N$-nitrosoguanidine (NTG) mutagenesis was performed as in Stalon et al. (1972). After three enrichment cycles using penicillin counterselection, suitable dilutions were plated on supplemented medium and mutants detected by replicaplating of the colonies. Mutants IRC204-7, IRC204-8 and IRC204-15 were selected for their inability to grow on guanidinobutyrate. Strain IRC204-28 was selected as a proline non-utilizing mutant, strain IRC204-202 as an ornithine non-utilizing mutant and strain IRC204102 for its poor growth on arginine.

Enzyme assays. Unless otherwise stated, assays were performed on cell extracts prepared by sonication of cells harvested in the exponential growth phase (Stalon et al., 1967) suspended in $50 \mathrm{~mm}$ potassium phosphate, $\mathrm{pH} 7.5$, containing $3 \mathrm{mM}-\beta$-mercaptoethanol. Cell debris was removed by centrifugation at $20000 \mathrm{~g}$ for $20 \mathrm{~min}$. Extracts were kept at $4{ }^{\circ} \mathrm{C}$. Protein concentrations were determined by the Lowry method. All enzymes were assayed at $30^{\circ} \mathrm{C}$. One unit of enzyme is defined as the amount of enzyme catalysing the formation of $1 \mu \mathrm{mol}$ of product $\mathrm{h}^{-1}$. Specific activities are units (mg protein $)^{-1}$. The various enzyme activities were assayed as follows. Enzymes involved in the arginine succinyltransferase pathway, namely arginine succinyltransferase (EC 2.1.3.-), $\quad N^{2}$-succinylarginine dihydrolase (EC 3.5.3.-), $N^{2}$-succinylornithine aminotransferase (EC 2.6.1.-) and $N$-succinylglutamate desuccinylase (EC 3.5.1.-) according to Vander Wauven \& Stalon (1985). Guanidinobutyrase (EC 3.5.3.7) was assayed under the conditions given by Miller \& Rodwell (1971) except that $4 \mathrm{~mm}-\mathrm{MnCl}_{2}$ was used in the assay; succinic semialdehyde dehydrogenase (EC 1.2.1.16) was determined from the increase in absorbance at $340 \mathrm{~nm}$ corresponding to NADP reduction (Jacoby, 1962). 4-Aminobutyrate transaminase (EC 2.6.1.19) was assayed according to Jacoby (1962) by coupling with succinic semialdehyde dehydrogenase. Ornithine cyclodeaminase (EC 4.1.1.17) and ornithine transaminase (EC 2.6.1.13) were assayed according to Stalon et al. (1987).

Analytical methods. The presence of urea in the culture supernatant was detected either by the colorimetric method of Archibald (1944) or of Prescott \& Jones (1969); guanidino- derivatives were determined according to Miklus \& Stein (1973). The presence of amino- and guanidino-derivatives was also identified by high voltage electrophoresis (Vander Wauven \& Stalon, 1985).

Chemicals. Amino acids, putrescine, 4-aminobutyrate, guanidinobutyrate, succinic semialdehyde, succinyl-CoA and aminooxyacetic acid were obtained from Sigma. Agmatine was purchased from Aldrich. $\mathrm{N}$ Carbamoylputrescine was prepared according to Mercenier et al. (1980) and 2-oxoarginine was obtained as described in Stalon \& Mercenier (1984). Succinylarginine, succinylornithine and succinylglutamate preparations were according to Vander Wauven \& Stalon (1985).

\section{Results and Discussion}

\section{Characterization of mutants}

$P$. putida mutants unable to use guanidinobutyrate as sole carbon and nitrogen source were obtained after mutagenesis with NTG followed by three penicillin enrichment cycles. Selection medium contained 20 mM-guanidinobutyrate as carbon and nitrogen source; enrichment medium was $20 \mathrm{~mm}$-succinate plus $10 \mathrm{~mm}$-ammonium salt. Among the mutants obtained $84 \%$ (65 mutants), represented by strain IRC204-7 were still able to use 4aminobutyrate as carbon and nitrogen source and grow at a reduced rate on arginine (Table 1 ); $8 \%$ (six mutants), represented by mutant IRC204-8 were unable to use guanidinobutyrate and arginine as sole carbon source, although they could use arginine as a nitrogen source; $8 \%$ (six mutants), represented by strain IRC204-15 had lost the ability to use both guanidinobutyrate and 4aminobutyrate - they were blocked in agmatine, carbamoylputrescine and putrescine utilization and also grew at a reduced rate on arginine (Table 1).

Mutant IRC204-102 was selected for its poor growth in the presence of arginine; the selection medium contained citrate and arginine, the enrichment medium contained putrescine.

Proline non-utilizing mutants were selected on $20 \mathrm{~mm}$ proline medium and enriched on glutamate medium. Mutant IRC204-28 is representative of this class of mutants; it is blocked in citrulline and ornithine utilization but grew well on arginine, agmatine or 2oxoarginine (Table 1). Mutants blocked between ornithine and proline were selected on ornithine medium and enriched on proline medium. The growth characterization of these mutant strains are summarized in Table 1.

\section{Enzyme activities in the arginine oxidase and arginine succinyltransferase pathways}

Enzyme activities of guanidinobutyrase, 4-aminobutyrate transaminase and succinic semialdehyde dehydrogenase in the arginine oxidase pathway as well as enzymes involved in the arginine succinyltransferase pathway were measured in wild-type and mutant strains after growth on various different media. The enzymes of the succinyltransferase pathway were induced in arginine medium and the specific activities varied considerably in the presence of different carbon sources (Table 2). There were no significant differences in enzyme synthesis between strains IRC204, IRC204-7 and IRC204-15 (data not shown). Mutant IRC204-102 is impaired in the succinylarginine dihydrolase activity whereas mutant 


\section{Table 1. Growth of wild-type and mutant strains}

Growth was followed in liquid medium 154 in the presence of $10 \mathrm{~mm}$-ammonium salt and the listed substrates tested at $20 \mathrm{~mm}$. Growth is indicated as +++ for good growth decreasing to + for poor growth and - indicating no growth. Tubes were incubated for 1 to $2 \mathrm{~d}$ at $30^{\circ} \mathrm{C}$. NT, Not tested.

\begin{tabular}{|c|c|c|c|c|c|c|c|}
\hline Growth substrate &  & 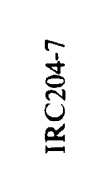 &  & 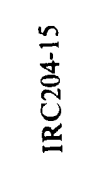 & 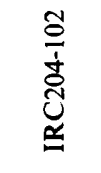 & 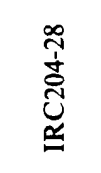 & 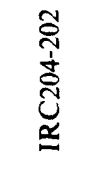 \\
\hline $\begin{array}{l}\text { Glutamate } \\
\text { L-Arginine } \\
\text { D-Arginine } \\
\text { Oxoarginine* } \\
\text { Agmatine } \\
\text { Carbamylputrescine } \\
\text { Putrescine } \\
\text { Guanidinobutyrate } \\
\text { 4-Aminobutyrate } \\
\text { Succinic semialdehyde } \\
\text { Citrulline } \\
\text { Ornithine } \\
\text { Proline }\end{array}$ & $\begin{array}{l}+++ \\
+++ \\
++ \\
+++ \\
+++ \\
+++ \\
+++ \\
+++ \\
+++ \\
++ \\
++ \\
++ \\
++\end{array}$ & $\begin{array}{c}+++ \\
+ \\
+ \\
- \\
+++ \\
+++ \\
+++ \\
+ \\
+++ \\
++ \\
+++ \\
++ \\
+++\end{array}$ & $\begin{array}{c}++ \\
- \\
- \\
- \\
+++ \\
+++ \\
+++ \\
- \\
+++ \\
++ \\
+++ \\
++ \\
+++\end{array}$ & $\begin{array}{c}++ \\
+ \\
+ \\
- \\
- \\
- \\
- \\
- \\
++ \\
++ \\
++ \\
++\end{array}$ & $\begin{array}{l}+++ \\
+ \\
+ \\
++ \\
+++ \\
+++ \\
+++ \\
+++ \\
+++ \\
++ \\
+++ \\
++ \\
++\end{array}$ & $\begin{array}{l}+++ \\
++ \\
++ \\
\text { NT } \\
+++ \\
+++ \\
+++ \\
+++ \\
+++ \\
++ \\
- \\
- \\
-\end{array}$ & $\begin{array}{l}+++ \\
++ \\
++ \\
\text { NT } \\
+++ \\
+++ \\
+++ \\
+++ \\
+++ \\
++ \\
- \\
+\end{array}$ \\
\hline
\end{tabular}

* Due to some contamination of oxoarginine by arginine, positive growth was indicated by disappearance of more than $90 \%$ of the guanidino- moiety with concomitant appearance of the urea formed. Negative growth was assumed if, after $3 \mathrm{~d}$ incubation, less than $15 \%$ of the guanidino- compound had been consumed.

Table 2. Enzyme synthesis in the arginine succininyltransferase pathway in P. putida IRC204

Cells were grown in minimal medium with the growth substrates listed. Values marked $a$ are taken from Stalon et al. (1987).

\begin{tabular}{|c|c|c|c|c|c|}
\hline \multirow[b]{2}{*}{ Strain } & \multirow[b]{2}{*}{$\begin{array}{c}\text { Growth } \\
\text { substrate(s) }\end{array}$} & \multicolumn{4}{|c|}{ Enzyme specific activity [units (mg protein) ${ }^{-1}$ ] } \\
\hline & & $\begin{array}{l}\text { Arginine } \\
\text { succinyl- } \\
\text { transferase* }\end{array}$ & $\begin{array}{c}\text { Succinyl- } \\
\text { arginine } \\
\text { dihydrolase } †\end{array}$ & $\begin{array}{l}\text { Succinyl- } \\
\text { ornithine } \\
\text { transaminase }\end{array}$ & $\begin{array}{c}\text { Succinyl- } \\
\text { glutamate } \\
\text { desuccinylase } \dagger\end{array}$ \\
\hline IRC204 & $\begin{array}{l}\text { Citrate }+\mathrm{NH}_{4}^{+} \\
\text {Guanidinobutyrate } \\
\text { Arginine } \\
\text { Citrulline } \\
\text { Ornithine } \\
\text { Arginine/glutamate }\end{array}$ & $\begin{array}{c}0 \cdot 2^{a} \\
0 \cdot 7 \\
12 \cdot 6^{a} \\
2 \cdot 2 \\
0 \cdot 8^{a} \\
6 \cdot 3\end{array}$ & $\begin{array}{r}0.9 \\
3 \cdot 0 \\
14 \cdot 5 \\
2 \cdot 3 \\
1 \cdot 3 \\
8 \cdot 5\end{array}$ & $\begin{array}{c}5 \cdot 0^{a} \\
3 \cdot 0 \\
20 \cdot 0^{a} \\
5 \cdot 6^{a} \\
2 \cdot 7^{a} \\
10 \cdot 1\end{array}$ & $\begin{array}{l}0.7 \\
0 \cdot 6 \\
7 \cdot 7 \\
1 \cdot 1 \\
1 \cdot 2 \\
6.5\end{array}$ \\
\hline IRC204-102 & Arginine & $11 \cdot 4$ & 0.05 & $18 \cdot 0$ & $5 \cdot 5$ \\
\hline IRC204-8 & Arginine/glutamate & $0 \cdot 2$ & 0.2 & $3 \cdot 0$ & $0 \cdot 2$ \\
\hline
\end{tabular}

* Mean values from at least duplicate independent experiments with less than $10 \%$ variation in activity.

$\dagger$ Values from a single experiment.

IRC204-8 has a severe reduction of all enzyme activities (Table 2).

Guanidinobutyrase, 4-aminobutyrate transaminase and succinate semialdehyde dehydrogenase were highly induced by growing wild-type cells on either 2-oxoarginine or guanidinobutyrate (Table 3 ). The levels of these enzymes were, however, lower on arginine medium.
Strain IRC204-102, affected in succinylarginine dihydrolase activity, had levels of all three enzymes similar to the wild-type strain, on arginine as well as on guanidinobutyrate medium (data not shown).

Strain IRC204-7 was impaired in guanidinobutyrase activity (Table 3). This mutant had the same level of transaminase and dehydrogenase activities on 4-amino- 
Table 3. Enzymes synthesis in the arginine oxidase pathway in P. putida IRC204

Cells were grown in minimal media with the growth substrates listed. Enzyme specific activities are mean values of at least two independent determinations with less than $10 \%$ variation in activity. NT, Not tested.

\begin{tabular}{|c|c|c|c|c|}
\hline \multirow[b]{2}{*}{ Strain } & \multirow[b]{2}{*}{ Growth substrate(s) } & \multicolumn{3}{|c|}{$\begin{array}{l}\text { Enzyme specific activity } \\
\text { [units (mg protein })^{-1} \text { ] }\end{array}$} \\
\hline & & $\begin{array}{c}\text { Guanidino- } \\
\text { butyrase }\end{array}$ & $\begin{array}{l}\text { 4-Amino- } \\
\text { butyrate } \\
\text { transaminase }\end{array}$ & $\begin{array}{c}\text { Succinic } \\
\text { semialdehyde } \\
\text { dehydrogenase }\end{array}$ \\
\hline \multirow[t]{10}{*}{ IRC204 } & Citrate $/ \mathrm{NH}_{4}^{+}$ & $0 \cdot 2$ & 1.9 & 11.5 \\
\hline & Guanidinobutyrate & $38 \cdot 0$ & $30 \cdot 0$ & $70 \cdot 0$ \\
\hline & Oxoarginine & $40 \cdot 0$ & NT & NT \\
\hline & 4-Aminobutyrate & $<0.2$ & $33 \cdot 0$ & $67 \cdot 0$ \\
\hline & Succinate semialdehyde $/ \mathrm{NH}_{4}^{+}$ & $<0.2$ & $2 \cdot 6$ & $28 \cdot 0$ \\
\hline & Agmatine & 0.5 & $20 \cdot 0$ & $89 \cdot 0$ \\
\hline & Putrescine & 0.2 & $18 \cdot 5$ & $33 \cdot 0$ \\
\hline & Arginine & $11 \cdot 5$ & $5 \cdot 1$ & $38 \cdot 0$ \\
\hline & Citrate/arginine & $5 \cdot 7$ & $3 \cdot 3$ & $18 \cdot 0$ \\
\hline & Citrate/guanidinobutyrate & $14 \cdot 0$ & $14 \cdot 0$ & $50 \cdot 0$ \\
\hline IRC204-7 & Citrate/arginine & $<0 \cdot 2$ & 0.7 & 13.4 \\
\hline IRC204-8 & Citrate/arginine & $<0.2$ & $0 \cdot 5$ & $8 \cdot 7$ \\
\hline IRC204-15 & Citrate/arginine & $<0 \cdot 2$ & $0 \cdot 1$ & $158 \cdot 0$ \\
\hline
\end{tabular}

butyrate medium as the wild-type strain (data not shown). When this mutant was grown on arginine, as no 4-aminobutyrate can be formed in vivo from arginine, a severe reduction in transaminase and dehydrogenase syntheses was observed (Table 3). Mutant IRC204-15 is affected in both guanidinobutyrase and transaminase activities. The fact that this strain was unable to use agmatine, carbamoylputrescine or putrescine, besides guanidinobutyrate and 4-aminobutyrate, indicates that the agmatine catabolic pathway converges to 4-aminobutyrate. In the wild-type strain, the inducing capacity of agmatine, putrescine, arginine or guanidinobutyrate for succinate semialdehyde dehydrogenase and 4-aminobutyrate transaminase may be related to the ability of these various growth substrates to be metabolized to 4aminobutyrate (Table 3). Nevertheless, mutant IRC20415 , affected in both guanidinobutyrase and transaminase activities had a derepressed dehydrogenase activity on arginine medium. This suggests that besides mutations in the structural genes, the general regulatory mechanism could be affected as well. The complete failure of mutant IRC204-8 to grow on arginine could be explained by the severe deficiency in both the arginine oxidase and the arginine succinyltransferase pathways (Tables 2 and 3 ). Multiple pathways for the catabolism of one amino acid may also lead to the isolation of mutants with lesions in the general control mechanism or in the transport system. Strain IRC204-8 could still use arginine as a nitrogen source. The non-induced levels of the enzymes in the two pathways, as well as that of arginine deiminase, were probably sufficient to account for growth with arginine as a nitrogen source. Growth was, however, distinctly slower with a generation time of $\geq 400 \mathrm{~min}$ on citrate plus arginine as compared to $60 \mathrm{~min}$ for the wild-type strain in the same conditions. This poor growth might reflect an impairment in the ability of the mutant to take up arginine so that the amount of arginine entering the cell was too low to allow induction of the catabolic enzymes.

\section{Growth characteristics of wild-type and mutant strains}

$P$. putida IRC204 grew on arginine as sole carbon and nitrogen source with a doubling time of $60 \mathrm{~min}$. Arginine utilization was characterized by an abundant excretion of urea. However, $P$. putida was able to use urea as sole nitrogen source; therefore quantitative analysis of excreted urea was followed in the presence of $10 \mathrm{mM}$ ammonium salt, thus imposing repression of urease (Tricot et al., 1990). Consequently, under these conditions the amount of urea excreted by cells of $P$. putida growing on arginine as sole carbon source is a rough estimate of the functioning of the arginine oxidase pathway. Careful analysis of arginine consumed and urea produced revealed that $60 \%$ of the guanidino group of arginine was found in the form of excreted urea. Among other products found in the spent culture and analysed by high voltage electrophoresis, there was some citrulline and ornithine produced by the non-induced levels of enzymes of the arginine deiminase route. 
Resting cells incubated with $10 \mathrm{~mm}$-arginine and $10 \mathrm{~mm}$ aminooxyacetic acid, an inhibitor of pyridoxal phosphate dependent enzymes (Wilson \& Holden, 1969), accumulated, besides urea, ornithine, citrulline, succinylornithine and 4-aminobutyrate, indicating that the arginine catabolic pathways are blocked at the level of succinyltransferase and 4-aminobutyrate transaminase. Another conclusion is that L-arginine is directly converted into 2-oxoarginine without $\mathbf{D}$-arginine as an intermediate as found in P. aeruginosa (Jann et al., 1987). D-Arginine is also a good carbon source for $P$. putida. Resting cells grown on D-arginine and incubated with $10 \mathrm{~mm}$-D-arginine $+10 \mathrm{~mm}$-aminooxyacetic acid did not accumulate urea, 4-aminobutyrate or succinylornithine. This is expected if a pyridoxal-phosphate-dependent racemase is involved in the interconversion of the enantiomers and D-arginine utilization involves Larginine as an intermediate.

Mutant IRC204-7 grew on arginine with a doubling time of $180 \mathrm{~min}$ whereas mutant IRC204-102 had a doubling time of $300 \mathrm{~min}$. This suggests that the contribution of the arginine succinyltransferase pathway to arginine utilization is more important than the oxidase route. However, this is in conflict with the results obtained on product excretion. Mutant IRC204-7 growing on arginine produced no urea but 2-oxoarginine, guanidinobutyrate and an unidentified guanidino- compound, probably guanidinobutyraldehyde. In contrast, when arginine $(10 \mathrm{mM})$ was entirely consumed by cells of strain IRC204-102, most of the guanidino- moiety was recovered as excreted urea $(55-60 \%)$ and $35-40 \%$ was recovered as succinylarginine. Consequently, the lower growth rate on arginine of strain IRC204-102 may be explained by consumption of succinyl-CoA which cannot be regenerated because of a defect in succinylarginine dihydrolase. It was previously shown for $P$. aeruginosa that addition of arginine to glutamategrowing cells of a mutant blocked in succinyldihydrolase arrests growth (Vander Wauven et al., 1988).

\section{Ornithine catabolism}

Ornithine is itself an important point of metabolic divergence since it is susceptible to several modes of enzymic conversion. Ornithine utilization may occur via arginine formation by the final steps of arginine synthesis. However, ornithine catabolism via arginine synthesis is unlikely since mutants blocked in either the arginine oxidase or the arginine succinyltransferase pathway still grow on ornithine as well as the wild-type strains does (Table 1): Transamination of ornithine to glutamate semialdehyde has been observed in many bacteria (see Cunin et al., 1986). An ornithine transamin- ase activity induced by arginine has been observed (Stalon et al., 1987). This activity was not synthesized by cells growing on ornithine. As in P. aeruginosa and other Pseudomonas strains having the arginine succinyltransferase pathway, this activity in $P$. putida was probably authentic succinylornithine transaminase (Stalon et al., 1987; Vander Wauven et al., 1988).

Although ornithine decarboxylase was detected in cell extracts, a pathway involving this enzyme appears an unlikely route for ornithine utilization as a carbon source since strain IRC204-15, a putrescine non-utilizing mutant, still grew on ornithine as a carbon source. Ornithine decarboxylase, which produces putrescine, is involved mainly in polyamine synthesis (see Cunin et al., 1986).

Cells grown on ornithine contained an induced level of ornithine cyclodeaminase activity (Table 4 ). The obligatory involvement of ornithine cyclodeaminase and proline in the catabolism of ornithine is indicated by the fact that mutant IRC204-202 is devoid of cyclodeaminase activity and does not use ornithine as a carbon source, whereas proline non-utilizing mutants represented by strain IRC204-28 are also unable to use ornithine (Table 4).

\section{Citrulline utilization and ornithine cyclodeaminase synthesis}

Citrulline is a good carbon source for $P$. putida (doubling time $60 \mathrm{~min}$ ) as compared to ornithine (doubling time $90 \mathrm{~min}$ ). The obligatory involvement of ornithine and proline in citrulline utilization is indicated by the observations that (i) ornithine cyclodeaminase was induced by growing cells on citrulline, and (ii) proline non-utilizing mutants, represented by strain IRC204-28 as well as strain IRC204-202 lacking ornithine cyclodeaminase activity, failed to grow on citrulline. Maximum induction of cyclodeaminase activity occurred with citrulline as sole carbon and nitrogen source (Table 4). The lower level of cyclodeaminase found in ornithinegrown cells might suggest that induction of the enzyme by ornithine was poor so that insufficient enzyme to support good growth was formed. Addition of proline to cells growing on ornithine resulted in a higher growth rate (doubling time $55 \mathrm{~min}$ ) and synthesis of ornithine cyclodeaminase. In Gram-negative bacteria proline regulates the osmotic equilibrium and may alter the permeability of the cytoplasmic membrane allowing solutes to permeate the cells more easily (Csonka, 1989). The stimulation of cyclodeaminase synthesis in argininegrown cells suggests that arginine might induce cyclodeaminase activity only by virtue of its conversion to citrulline or ornithine mediated by the arginine deimin- 
Table 4. Regulation of ornithine cyclodeaminase synthesis in P. putida IRC204

Cells were grown in minimal medium with the growth substrate(s) listed. Except for the two values marked with an asterisk $\left({ }^{*}\right)$, which are from a single experiment, the values shown are means from two independent experiments (enzyme assays done in duplicate); variation was less than $10 \%$.

\begin{tabular}{llc}
\hline \hline Strain & Growth substrate(s) & $\begin{array}{c}\text { Enzyme specific activity } \\
\text { [units (mg protein) }\end{array}$ \\
\hline IRC204 & Citrate + NH & $<0 \cdot 05$ \\
& Citrulline & $7 \cdot 2$ \\
& Ornithine & $2 \cdot 0$ \\
& Arginine & $4 \cdot 1$ \\
& Citrulline + ornithine & $9 \cdot 9$ \\
& Citrulline + proline & $6 \cdot 2$ \\
& Ornithine + proline & $9 \cdot 0$ \\
& Proline & $<0.05$ \\
& Citrulline + citrate & $5 \cdot 8^{*}$ \\
& Citrulline + NH & $6 \cdot 6$ \\
& Citrulline + glutamate & $6 \cdot 0$ \\
& Citrulline + citrate $+\mathrm{NH}_{4}^{+}$ & $5 \cdot 8^{*}$ \\
& Citrulline + glutamine & 3.9 \\
& Citrulline + citrate + glutamine & $3 \cdot 0$ \\
IRC204-28 & Citrulline + glutamate & $5 \cdot 5$ \\
IRC204-202 & Citrulline + glutamate & $<0 \cdot 1$ \\
\hline \hline
\end{tabular}

ase pathway. Some citrulline was always found to be excreted from cells growing on arginine under aerobiosis whereas abundant ornithine excretion was observed in cells grown on arginine during an anaerobic shock (Stalon \& Mercenier, 1984). The activity responsible for citrulline/ornithine interconversion is probably the catabolic ornithine carbamoyltransferase (OTCase). Consequently, catabolic OTCase fulfills two functions: one is the utilization of arginine for synthesis of ATP in anaerobiosis (Stalon \& Mercenier, 1984); the second concerns citrulline utilization in aerobiosis. Mutants affected in the structural gene encoding catabolic OTCase will be of interest to determine the physiological role of this enzyme as well as the distribution of the arginine flux along this pathway in $P$. putida.

\section{Conclusions}

The results of this study show that both the oxidase and the arginine succinyltransferase pathways are essential for sustaining full wild-type growth rates on arginine used as sole carbon source. The loss of one pathway by deficiency in a structural gene causes bradytrophic growth. The neotype strain $P$. putida ATCC 12633, as well as strain ATCC 25571 (isolated by Miller \& Rodwell, 1971), in which the arginine oxidase route was identified, also have both pathways (unpublished observations). Most Pseudomonas strains use only the arginine succinyltransferase route for aerobic argin- ine utilization (Stalon et al., 1987), although the pathway leading to guanidinobutyrate is cryptic in some strains (Jann et al., 1988; Yorifuji et al., 1983).

Another characteristic typical of $P$. putida when compared to other Pseudomonas strains is its ability to use citrulline as sole carbon source. Citrulline utilization involves ornithine and proline as intermediates whereas most Pseudomonas strains use the ornithine succinyltransferase pathway. $P$. putida converts ornithine to proline by means of ornithine cyclodeaminase, an activity which is also found in Clostridium sporogenes (Costilow \& Laycock, 1969, 1971), Treponema denticola (Leschine \& Canale-Parola, 1980), Agrobacterium tumefaciens (Dessaux et al., 1986) and P. cepacia (Stalon et al., 1987).

This work was supported by grant 2.9003.88 from the Belgian Fund for Joint Basic Research and by an Action de Recherche Concertée financed by the French Community of Belgium. V.S. is a Research Associate of the National Fund for Scientific Research (Belgium).

\section{References}

ARChibald, R. M. (1944). Determination of citrulline and allantoin and demonstration of citrulline in blood plasma. Journal of Biological Chemistry 156, 121-142.

Costilow, R. N. \& LAYCOCK, L. (1969). Reactions involved in the conversion of ornithine to proline in clostridia. Journal of Bacteriology 100, 622-667.

CostiLow, R. N. \& LAYCOCK, L. (1971). Ornithine cyclase (deaminating): purification of a protein that converts ornithine to proline and definition of optimal assay conditions. Journal of Biological Chemistry 246, 6655-6660. 
Csonka, L. (1989). Physiological and genetic response of bacteria to osmotic stress. Microbiological Reviews 53, 121-127.

Cunin, R., Glansdorff, N., Pierard, A. \& Stalon, V. (1986). Biosynthesis and metabolism of arginine in bacteria. Microbiological Reviews 50, 314-352.

Dessaux, Y., Petit, A., Tempe, J., Demarez, M., Legrain, C. \& Wiame, J. M. (1986). Arginine catabolism in Agrobacterium tumefaciens: role of the Ti-plasmid. Journal of Bacteriology 166, 4450 .

JAKOBY, W. B. (1962). Enzymes of $\gamma$-aminobutyrate metabolism (bacterial). Methods in Enzymology 5, 767-778.

JanN, A., Matsumoto, H. \& HaAs, D. (1988). The fourth arginine catabolic pathway of Pseudomonas aeruginosa. Journal of General Microbiology 134, 1043-1053.

JanN, A., Stalon, V., Vander Wauven, C., Leisinger, T. \& HaAs, D. (1986). Succinylated intermediates in an arginine catabolic pathway of Pseudomonas aeruginosa. Proceedings of the National Academy of Sciences of the United States of America 83, 4937-4941.

Leschine, S. B. \& Canale-Parola, E. (1980). Ornithine dissimilation by Treponema denticola. Current Microbiology 3, 305-310.

Mercenier, A., Simon, J. P., HaAs, D. \& Stalon, V. (1980). Catabolism of L-arginine by Pseudomonas aeruginosa. Journal of General Microbiology 116, 381-389.

Micklus, J. M. \& SteIN, I. (1973). The colorimetric determination of mono and disubstituted guanidines. Analytical Biochemistry 54, 545553.

MILLER, D. L. \& RoDWell, V. W. (1971). Metabolism of basic amino acids in Pseudomonas putida. Journal of Biological Chemistry 246, 5053-5058.

PrescotT, L. M. \& Jones, M. E. (1969). Modified methods for determination of carbamylaspartate. Analytical Biochemistry 32 , 408-419.
Stalon, V., Ramos, F., Pierard, A. \& Wiame, J. M. (1967). The occurrence of a catabolic and an anabolic ornithine carbamoyltransferase in Pseudomonas fluorescens. Biochimica et Biophysica Acta 139, 91-97.

Stalon, V., Ramos, F., Pierard, A. \& Wiame, J. M. (1972). Regulation of the catabolic ornithine carbamoyltransferase in Pseudomonas fuorescens: a comparison with the anabolic transferase and with a mutationally modified catabolic transferase. European Journal of Biochemistry 29, 25-35.

Stalon, V. \& Mercenier, A. (1984). L-Arginine utilization by Pseudomonas species. Journal of General Microbiology 130, 69-76.

Stalon, V., Vander Wauven, C., Momin, P. \& Legrain, C. (1987). Catabolism of arginine, citrulline and ornithine by Pseudomonas and related bacteria. Journal of General Microbiology 133, 2487-2495.

Tricot, C., Pierard, A. \& Stalon, V. (1990). Comparative studies on the degradation of guanidino and ureido compounds by Pseudomonas. Journal of General Microbiology 136, 2307-2317.

Vander Wauven, C. \& Stalon, V. (1985). Occurrence of succinyl derivatives in the catabolism of arginine in Pseudomonas cepacia. Journal of Bacteriology 164, 882-886.

Vander Wauven, C., Jann, A., HaAs, D., Leisinger, T. \& Stalon, V. (1988). $N^{2}$-succinylornithine in ornithine catabolism of Pseudomonas aeruginosa. Archives of Microbiology 150, 400-404.

Wilson, O. H. \& Holden, J. T. (1969). Arginine transport and metabolism in osmotically shocked and unshocked cells of Escherichia coli W. Journal of Biological Chemistry 244, 2737-2742.

Yorifuni, T., Kobayashi, T., Tabuchi, H., Shiritani, Y. \& Yonaha, K. (1983). Distribution of amidinohydrolases among Pseudomonas and comparative studies of some purified enzymes by one dimensional peptide mapping. Agricultural and Biological Chemistry 47, 2825-2830. 